\title{
Addressing potential sources of variation in several non-destructive techniques for measuring firmness in apples
}

\author{
D. Molina-Delgado , S. Alegre, P. Barreiro , C. Valero, M. Ruiz-Altisent , I. Recasens' \\ HBJ Department, University of Lleida, Lleida, Spain \\ Postharvest Area, Centre UdL-IRTA University of Lleida, Lleida, Spain \\ Experimental Station of Lleida, IRTA, Spain \\ Rural Engineering Department, Physical Properties Laboratory, Polytechnic University of Madrid, Madrid, Spain
}

\begin{abstract}
Measurements of firmness have traditionally been carried out according to the Magness Taylor (MT) procedure; using a texture analyser or penetrometer in reference texture tests. Non-destructive tests like the acoustic impulse response of acoustic firmness sensors (AFSs), a low-mass impact firmness sensor Sinclair International (SIQ-FT) and impact test (Lateral Impact - UPM) have also been used to measure texture and firmness. The objectives of this study were to evaluate the influence of different sources of variation in these three non-destructive tests and to evaluate their respective capabilities of discriminating between fruit maturity at two different harvest dates, turgidity before and after dehydration treatment and ripening after different storage periods. According to our results, fruit studied an unexpected AFS trend with turgidity. Contact measurements (Lateral Impact - UPM and SIQ-FT) appeared highly sensitive to changes in turgidity, but were less able to follow changes in ripening caused by storage period. Contact measurements were suitable for detecting differences between fruits from different harvest dates and showed higher correlation coefficients with reference texture tests than acoustic measurements. The Lateral lmpact - UPM test proved better at separating fruits according to turgidity than the SIQ-FT instrument.
\end{abstract}

\section{Introduction}

Firmness is the key factor in deciding whether a fruit will be accepted by the consumer because it is related to postharvest ripeness and storage conditions. Determining the effect of storage time on the evolution of fruit quality is a desirable objective for all producers, distributors and market agents, who need reliable measuring instruments for commercial purposes.
Numerous devices have been proposed and used for measuring fruit firmness. Measurements of firmness have traditionally been carried out following the Magness Taylor (MT) procedure, using either a texture analyser or hand-held penetrometers to measure maximum penetration force and other related parameters (reference texture tests). The MT test measures the maximum force required to penetrate with a rounded plunger of $8 \mathrm{~mm}$ or $11 \mathrm{~mm}$ (depending of the fruit) diameter. The resistance of fruit flesh to penetration can then 


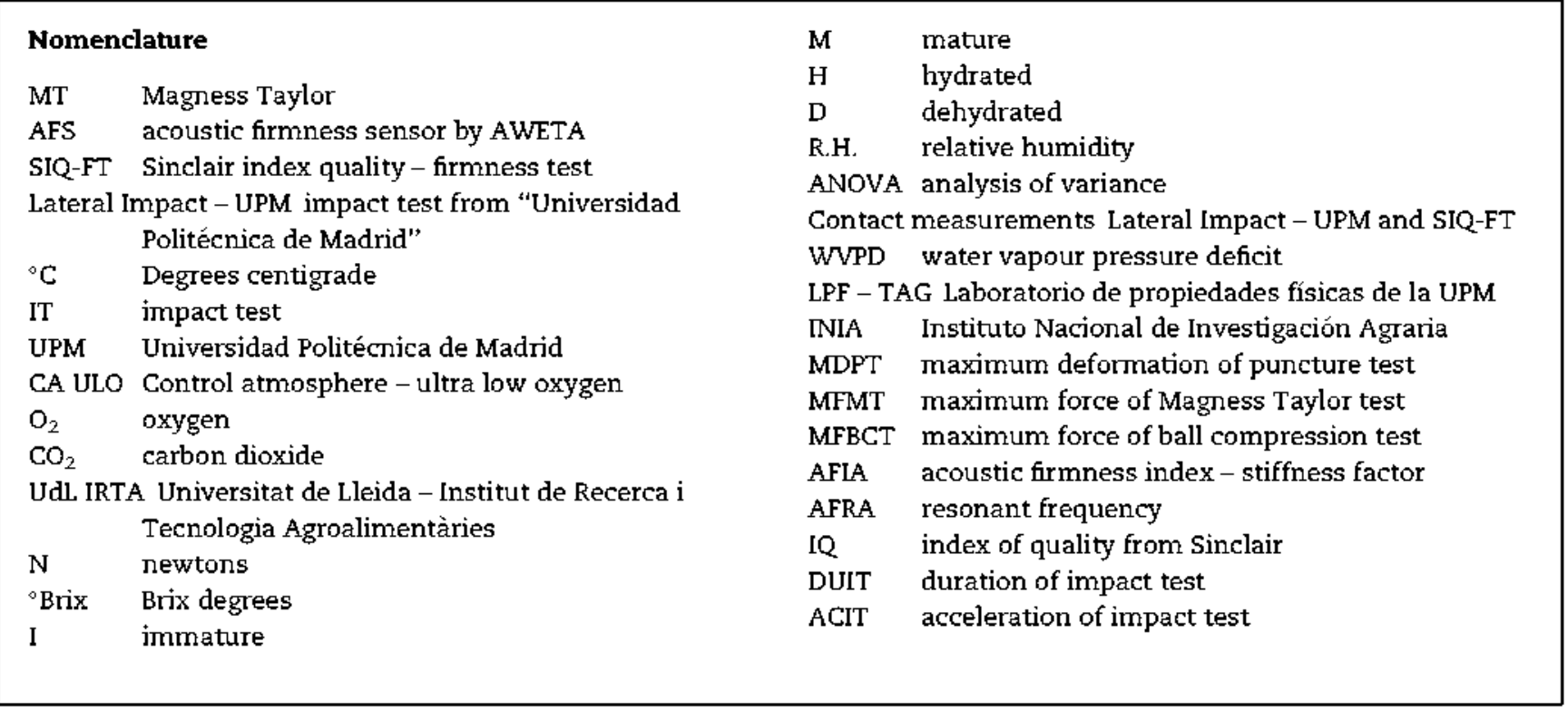

be evaluated and related to cell wall thickness and the resistance of intercellular bindings (Landahl et al., 2003). This measurement is local, influenced by both the operator and the rate of loading, and sometimes fails to give enough information about the global quality of the fruit or changes related to ripening processes going on within the fruit.

Firmness is one of the most common physicochemical parameters used to evaluate fruit quality but does not take into account all aspects of fruit texture, as texture is a difficult concept to define. It is related to the mechanical quality of fruit and as such is influenced by a combination of properties (Diezma, 2004) that relate to the fruit's ability to resist mechanical deformation.

Studies of the textural attributes of fruit and vegetables must consider the relationships between texture and maturity processes. Several authors have already studied the influence of humidity and temperature, water status, and apoplastic and symplastic water on changes in texture (De Smedt et al., 2002; Herppich et al., 2003; Hertog et al, 2004). The effects on turgor pressure within the cell, physical components of the cell wall, and the properties and tissue structure that determine tensile strength, firmness and elasticity, combine to characterize texture. Cultivar type has a major influence on changes in tissue properties and their relation to variations in temperature. Storage time is also a relevant factor in response to changes in temperature, though this response does not appear to correlate significantly with orchard and harvest maturity (Johnston et al., 2001). Numerous interactions amongst the previously mentioned factors and properties make it difficult to study texture.

The instrumental estimation of fruit textural properties is based on the mechanical response of fruit tissues. Each fruit has different properties but usually fresh recently harvested fruit present an elastic deformation, while this changes into plastic properties during the ripening process. To study the textural properties such as firmness, hardness or fragility of the fruit, a set of different mechanical tests are used as reference texture tests (Mohsenin, 1970). Some of the most accepted tests are the ball compression test, which relates to tactile texture, skin puncture test, which relates to the resistance of the skin and the turgor of the superficial tissues of the flesh, and MT test equivalent to a penetration test with manual penetrometer (Boume, 1966; Valero, 2001). The device commonly used to carry out this texture test is a texture analyser, XT2, universal testing machine with a texture analyser microprocessor (Diezma-Iglesias et al, 2006).

Measuring firmness by the MT method has the disadvantages of being destructive and time consuming. As a result, new technologies have recently focused on developing accurate non-destructive techniques for measuring fruit quality and, more specifically, texture and firmness properties. The main advantages of non-destructive measurements as opposed to reference techniques are that they are quick, repeatable, easily installed online and allow continuous evaluation of firmness on different parts of the same fruit without producing fruit waste and subsequent losses. These techniques have been applied using different approaches. The most widely studied are as follows: non-destructive firmness sensors based on acoustic impulse response (AFS by AWETA); the measurement of tissue impact response for micro-deformation on the fruit surface by Sinclair International (SIQ-FT); and recording the duration and acceleration curve during an impact test (Lateral Impact - UPM). Several sources of variation influence the results obtained with these techniques. Sometimes uncertainty (measurement error) may be larger than true fruit heterogeneity (De Ketelaere et al., 2006). It is also important to note that non-destructive measurements do not necessarily measure the same properties as the penetrometer MT test. This explains the observed differences in the relationships between reference and non-destructive measurements of firmness reported by several authors working with different products and under different experimental conditions (De Belie et al, 2000; Shmulevich, 2003; Valente \& Ferrandis, 2003; Golding et al., 2005; Zude et al., 2006). 


\subsection{Acoustic measurements}

The acoustic response technique as an alternative method for measuring fruit texture and firmness has been studied from two different approaches: a technique using ultrasound and an acoustic technique involving values within the audible spectrum. As noted by Shmulevich (2003), the texture and quality of several fruits have been studied using this technique, by an extensive group of researchers. Recently, with the development of commercial portable devices, several authors have studied the utility of this technique: for modelling the softening of apples during storage and ripening (Roth et al, 2003; Shmulevich et al., 2003; Gómez et al., 2005; De Ketelaere et al., 2006; Zude et al., 2006); for monitoring the evolution of firmness in pears on the tree to determine optimum harvest date (De Belie et al., 2000); for evaluating the water status of fruits and vegetables (Herppich et al., 2003; Hertog et al., 2004; Landahl et al., 2004); and also to introduce this technique as a tool for classifying good and hollow water melon (Diezma-Iglesias et al., 2004).

Acoustic firmness index is based on the relationship between Young's modulus and the resonant frequencies of the various spherical mode shapes of vibration of the fruit. The natural frequencies of the intact fruit are obtained by performing a Fourier transformation of the signal recorded after hitting the fruit. Chen \& De Baerdemaeker (1993) used the first resonant frequency and the mass of the fruit to calculate acoustic firmness index, which Roth et al. (2003) reported as Eq. (1)

$\operatorname{AFIA}=\operatorname{AFRA}^{2} m^{2 / 3}$

where AFIA is the acoustic firmness index or stiffness factor in $\mathrm{kg}^{2 / 3} \mathrm{~s}^{-2}$, AFRA is resonant frequency $(\mathrm{Hz})$ and $m$ is mass $(\mathrm{kg})$.

Because acoustic firmness index is not a local measure and obtains information from the whole fruit, it is affected by several sources of variation, some of which, such as weight and shape, are inherent to the morphological characteristics of different fruits. Other factors, such as the temperature and humidity of the fruit, are related to storage conditions. Evaluating acoustic firmness index in fruits is therefore a complex task. Apart from cultivar, the most frequently analysed sources of variation in studies of fruit firmness that employ acoustic techniques relate to harvest time, storage time, storage conditions and different shelf life duration.

As Gómez et al. (2005) reported, the first operational problems that affect acoustic measurement and needed to be avoided concern shape, fruit mass and the position of the impact, especially for non-spherical fruits. Research into potential sources of variation associated with this technique then focused on factors related to harvest and storage conditions. De Belie et al. (2000) found that the main factor that influenced acoustic measurements in conférence and Doyenne du Comice pears was harvest date, with cultivar and season being less relevant. Roth et al. (2003), in a study with Pinova and Liberty apples, and Shmulevich et al. (2003) found that cultivar was an equally important source of variation.

Some aspects related to water loss, turgor and elastic properties were studied in depth in radish by Herppich et al. (2003) and landahl et al. (2004). They concluded that acoustic firmness index was not a true indicator of mean tuber elastic properties. They also concluded that duration of storage was the main reason for apparent contradictions in published data that claim acoustic measurements can be used to evaluate changes in tissue firmness in different fruits. According to their conclusions, the modulus of elasticity is closely related to changes in short-term water status (water potential), while acoustic firmness index is more related to water content and cell wall properties that present long-term variations. Storage duration is therefore an important source of variation in acoustic measurements. In their studies with peaches and different varieties of apples, Diezma et al. (2005), De Ketelaere et al. (2006), and Zude et al. (2006) agreed on the importance of storage duration as a source of variation. Water loss by Tradiro tomatoes and Jonagold apples (after 6 months of storage) seemed to be the most important source of variation affecting acoustic measurements according to Hertog et al. (2004). They concluded that these water losses were, in turn, affected by temperature and relative humidity (R.H.). According to Gómez et al. (2005), at a normal storage temperature $\left(4^{\circ} \mathrm{C}\right)$, storage period is the main factor affecting acoustic measurements for China pearl pears.

\subsection{Low-mass impact system (SIQ-FT)}

As Shmulevich et al. (2003) reported, De Baerdemaeker et al. (1982) and Delwiche (1987) had dropped fruit onto a transducer in order to get information about its quality. Chen and Tjan (1998) used low-mass devices to apply an impact to fruit and then correlated the response with firmness and several other fruit texture properties. More recently, Sinclair International ltd. reviewed all of these previous experiences and developed a device that measures firmness by fruit response to a low impact induced using a force transducer. Since then, other researchers have used this technique to model the softening process during storage and ripening in apples and tomatoes (Shmulevich, 2003; Shmulevich et al, 2003; Golding et al., 2005; De Ketelaere et al., 2006) and to monitor the evolution of firmness in peaches (Valero et al., 2004).

The head of the SIQ-FT pneumatically-operated sensor is equipped with a piezo, or ceramic generator, which is pushed out of the lower end each time that the device hits a sample fruit. The electronic sensor converts force to a voltage signal and this signal is converted and processed by specifically designed software in order to return a measurement that expresses fruit firmness as an indexed number ranging from 0 to 100 (arbitrary units), with soft fruits having low index numbers (Valero et al., 2003).

Several authors have reported different sources of variation in measurements when using this device. Most agree that storage period, ripening and maturity stage are the most relevant sources of variation (Shmulevich, 2003; Shmulevich et al, 2003; Valero et al., 2003; Golding et al., 2005; De Ketelaere et al., 2006), although fruit and cultivar are also reported as important (Shmulevich, 2003; Shmulevich et al., 2003; Valero et al, 2003).

\subsection{Impact test (IT)}

Parallel to the development of the acoustic technique and the Sinclair impact device, several other techniques, also based on 
impact tests, were studied by Delwiche (1987), Delwiche et al. (1996), Chen et al. (1985) and Chen et al. (1993) in order to correlate fruit firmness and impact response parameters such as maximum force, maximum deformation and duration of impact. It had been found that the impact of a fruit on a rigid surface can be closely modelled by the impact of an elastic sphere and that the firmness of a fruit has a direct effect on the impact force response. Using a small spherical impactor of known mass and radius of curvature and measuring the acceleration of the impactor resulted in a better way to estimate firmness because the acceleration response is independent of the fruit mass and less sensitive to the variation of the radius of curvature of the fruit (Diezma-Iglesias et al., 2006).

Using this principle, an impact device for firmness testing of fruits was developed by Chen and Ruiz-Altisent (1996). This device consisted of a semi-spherical impacting tip attached to the end of a pivoting arm. Impact is made by swinging the impactor to collide laterally with the tested fruit. A small accelerometer is mounted behind the impactor tip. Improved versions of this tool have been developed in the physical properties laboratory of UPM. The non-destructive impact test uses the dynamic point of fluency as a criterion for establishing the resistance to damage of fruits under dynamic conditions. With this equipment, it is possible to determine the dynamic firmness of a fruit through a combination of its deformability and the duration of the contact. The evolution of this technique has demonstrated its ability to predict compression force in peaches (Diezma et al., 2005), classify fruits, and, follow changes during apple and pear nipening Jaren \& García-Pardo, 2002).

With this technique, the main sources of variation reported by different authors were fruit type (Jaren \& García-Pardo, 2002), cultivar (Steinmetz et al., 1996; Jaren \& García-Pardo, 2002; Diezma et al., 2005), harvest date (Steinmetz et al., 1996), maturity stage, storage conditions and storage period (Jaren \& García-Pardo, 2002; Diezma et al., 2005).

In a previous study, carried out over a period of three years, we evaluated the acoustic firmness of Golden Smoothee and Gala apples from six harvest dates and 12 orchards. In total we studied 8600 fruits of each cultivar and evaluated them at harvest and after 8 months in cold storage in a controlled ultra low oxygen atmosphere (CA-ULO) $\left(0.5^{\circ} \mathrm{C} ; 1 \% \mathrm{O}_{2} ; 1 \% \mathrm{CO}_{2}\right)$. The results of this study showed differences not only in the relationship between MT and acoustic firmness index, but also in the trend of acoustic firmness index for different varieties, stages of maturity and storage periods. The ability of this technique to describe changes in apples during harvest and after storage was not clearly demonstrated (Molina-Delgado et al., 2009). We therefore decided to carry out this test with Golden Smoothee under controlled conditions: monitoring maturity at harvest, ripening before and after the storage period and turgidity both with and without dehydration.

The main objective of this study was to evaluate the influence of different sources of variation on the results obtained when applying the acoustic firmness sensor (AFS) and the SIQ-FT and Lateral Impact-UPM impact tests. The relationships between all of the variables in the non-destructive tests, reference texture tests and quality measurements were studied.

\section{Materials and methods}

The apples (Malus domestica. Borkh cv. Golden Smoothee) were grown at the UdL - IRTA experimental station in Lleida, Spain. A factorial design with three factors was chosen: maturity at harvest corresponding to different harvest dates, turgidity stage, and storage period (Table 1).

Fruit were harvested on two different dates: 27 th September $\left(56.43 \pm 0.66 \mathrm{~N}\right.$ of firmness, $13.70 \pm 0.08^{\circ}$ Brix of soluble solids and $6.80 \pm 0.30$ starch index) and 8th October ( $48.91 \pm 0.66 \mathrm{~N}$ of firmness, $15.60 \pm 0.09^{\circ}$ Brix of soluble solids, and $8.1 \pm 0.2$ starch index), from here on referred to as immature (I) and mature (M), respectively. Fruit were harvested according to a completely randomized design: six batches of 10 fruits each were harvested on each harvest date (two harvest dates, with a total of 120 fruits). For each harvest date, three batches were subjected to a treatment with hot flowing air at $35^{\circ} \mathrm{C}$ (using a household fan) for $48 \mathrm{~h}$ to induce differences in turgidity. This treatment generated a loss of turgor in superficial apple tissues. The differences in turgidity between treated and untreated fruits are referred to in this study as relating to hydrated $(H)$ and dehydrated fruits (D). From the total six batches for each harvest date, two batches ( $\mathrm{H}$ and $\mathrm{D})$ were analysed at harvest (time 0 ), two batches $(\mathrm{H}$ and $\mathrm{D})$ were analysed after 30 days of storage and two batches ( $\mathrm{H}$ and $\mathrm{D})$ were analysed after 60 days of storage. Storage conditions were $1^{\circ} \mathrm{C}$ and $92 \%$ R.H. (Table 1).

These batches will be referred to as: MOD, IOD, MOH, IOH, M3D, I3D, M3H, I3H, M6D, I6D, M6H and I6H.

Table 2 summarizes the tests carried out on these samples with their corresponding labels: quality measurements (soluble solid content, starch index and acidity), reference texture tests (puncture test, MT test and ball compression test) and nondestructive techniques (AFS, Lateral Impact - UPM and SIQ-FT).

All measurements, reference texture test and nondestructive test were carried out for each fruit in three

Table 1 - Experimental design. Batches of 10 fruit (10 f)

Maturity stage

\begin{tabular}{|c|c|c|c|c|c|}
\hline \multicolumn{3}{|c|}{ Immature (harvest: 27 th Sep.) } & \multicolumn{3}{|c|}{ Mature (harvest: 8 th Oct.) } \\
\hline \multirow{2}{*}{$\begin{array}{l}\text { Storage (days) } \\
0\end{array}$} & \multicolumn{2}{|c|}{ Turgidity (hydration treatment) } & \multirow{2}{*}{$\begin{array}{c}\text { Storage (days) } \\
0\end{array}$} & \multicolumn{2}{|c|}{ Turgidity (hydration treatment) } \\
\hline & Dehydrated & Hydrated & & Dehydrated & Hydrated \\
\hline 30 & Dehydrated & Hydrated & 30 & Dehydrated & Hydrated \\
\hline 60 & Dehydrated & Hydrated & 60 & Dehydrated & Hydrated \\
\hline
\end{tabular}


Table 2 - Variables used, codes and units

\begin{tabular}{|c|c|c|}
\hline Name of variable & Code & Units \\
\hline \multicolumn{3}{|l|}{ Quality measurements } \\
\hline Soluble solids content & SSC & ${ }^{\circ} \mathrm{Bjix}$ \\
\hline Starch index & SI & EUROFRU scale \\
\hline Acidity & AC & $\mathrm{g}_{\text {malic acid }} \mathrm{l}^{-1}$ \\
\hline \multicolumn{3}{|l|}{ Reference texture test } \\
\hline \multicolumn{3}{|l|}{ Puncture test } \\
\hline Maximum deformation & MDPT & $\mathrm{mm}$ \\
\hline \multicolumn{3}{|l|}{ MT test } \\
\hline Maximum force & MFMT & $N$ \\
\hline \multicolumn{3}{|l|}{ Ball compression test } \\
\hline Maximum force & MFBCT & $\mathbf{N}$ \\
\hline \multicolumn{3}{|l|}{ Non-destructive variables } \\
\hline AFS by AWETA & AFS & \\
\hline Acoustic firmness & AFIA & $10^{6} \mathrm{~Hz}^{2} \mathrm{~g}^{2 / 3}$ \\
\hline Acoustic frequency & AFRA & $\mathrm{Hz}$ \\
\hline Impact test by Sinclair $\mathrm{JQ}^{\mathrm{M}}$ & Sinclair IQ & \\
\hline Index of quality & $1 Q^{T N}$ & - \\
\hline Impact test & $\begin{array}{l}\text { Lateral } \\
\text { lmpact - UPM }\end{array}$ & \\
\hline Acceleration & ACIT & $\mathrm{ms}^{-2}$ \\
\hline Duration & DUIT & ms \\
\hline
\end{tabular}

repetitions, from the less destructive to the most destructive. The sequence of testing was: AFS, Lateral Impact - UPM, SIQFT, puncture test, ball compression test and MT test.

\subsection{Quality measurements}

Soluble solids content, titratable acidity and starch index were evaluated at harvest ( 0 days). The starch index was evaluated with iodine using the EUROFRU scale ranging from $1(100 \%$ starch) to 10 ( $0 \%$ starch). Soluble solid content was measured with a digital temperature-compensated refractometer (Mode] PR-101, Atago Co., Tokyo, Japan) using fresh juice from individual fruits ground in an electric juice extractor. Titratable acjdity (expressed as malic acid) was determined by titrating $10 \mathrm{ml}$ of juice with $1.0 \mathrm{M} \mathrm{NaOH}$ to $\mathrm{pH} 8.2$. Three repetitions per fruit were carried out for quality measurements.

\subsection{Reference texture tests}

A texture analyser (TA-XT2, Stable Micro System Ltd.) was used to perform three mechanical tests: ball compression, MT penetration and skin puncture tests were carried out in three replicates at the equatorial zone of each fruit.

\subsubsection{Ball compression test}

UPM: a $1.8 \mathrm{~mm}$ diameter spherical rod was used to deform the surface of the fruit at a speed of $20 \mathrm{~mm} \mathrm{~min}^{-1}$ until achieving a deformation of $2 \mathrm{~mm}$. Parameters such as maximum force during the test (N), adsorbed energy during the load/unload cycle ( $\mathrm{Nmm}$ ) and elasticity index (\% of proportion of recovered deformation over total deformation) were obtained from a force deformation curve.

\subsubsection{Skin puncture test - UPM}

A $0.5 \mathrm{~mm}$ diameter cylindrical rod was used to carry out the test, which finished when $8 \mathrm{~mm}$ of penetration was achieved at a speed of $20 \mathrm{mmmin}^{-1}$. Deformation at the point of maximum force (mm) was obtained from the force/deformation curve. This test is used to estimate the turgor of the fruit surface (García et al., 1995).

\subsubsection{MT test}

An $11 \mathrm{~mm}$ diameter cylindrical rod with a rounded head was used to perform the test on the mesocarp. The test finished when the rod reached a depth of $8 \mathrm{~mm}$ at a speed of $20 \mathrm{~mm} \mathrm{~min}^{-1}$. In each case, maximum penetration force (N) was obtained from a force/deformation diagram.

\subsection{Non-destructive methodologies}

\subsubsection{Acoustic measurements, AFS by AWETA (Model DTF V0.0.0.82)}

This test was carried out on individual fruits. Three repetitions within the equatorial zone were carried out for each fruit. The fruit was positioned to receive a low impact within its equatorial zone. The impact was provided by a plastic piston with a spherically shaped end that generated an acoustic response from the fruit. This response was detected and registered by a microphone located near, but not in contact with, the fruit surface and acoustic firmness index, AFIA and acoustic frequency, AFRA were determined.

\subsubsection{Contact measurements}

2.3.2.1. Low-mass impact by Sinclair IQ. Sinclair international quality firmness tester (SIQ-FT, Sinclair Systems International, LLC, Fresno, CA) was applied at three points within the equatorial zone of the fruit. The device is based on a low-mass sensing element, placed inside the Sinclair patented air bellow, hitting the fruit by air pressure and the impact signal is captured. A special data acquisition and signal analysis program was employed to determine internal quality index (IQ $\left.{ }^{\mathrm{TM}}\right)$ of the tested sample. The $\mathrm{IQ}^{\mathrm{IM}}$ value is calculated according to the impact signal as a dynamic measure of fruit tissue spring constant $\left(\sim \mathrm{N} \mathrm{mm}^{-1}\right)$, and can be expressed by the equation:

$\mathrm{IQ}^{\mathrm{Ts}}=\mathrm{C} *\left(P_{\max } / \int p(t) d t\right)^{2}$

where $C$ is a system constant, $P_{\max }$ the peak amplitude of the impact response and $p(t)$ the impact response as a function of time.

The distances between the impactor rubber supporting the sensor and the impact point on the surface of the fruit were maintained at $2.5 \mathrm{~mm}$. Vacuum and pressure were adjusted to within $\pm 199075 \mathrm{~Pa}$. The IQ value was obtained.

2.3.2.2. Impact test (Lateral - UPM). "LPF Lateral Impact Sensor $2.0^{*}$ was used. It consists of spherical mass of $10 \mathrm{~g}$, which impacts the sample, with a piezoelectric accelerometer of a sensitivity of $1 \mathrm{mV} \mathrm{m}^{-1} \mathrm{~s}^{-2}$ and a range of $\pm 4900 \mathrm{~m} \mathrm{~s}^{-2}$ ENDEVCO Model 256-10 (manufactured by ENDEVCO SAN JUAN CAPISTRANO, CA 92675 , USA); a spring to release the 
impacting mass; and an electromagnet to hold the impact mass. The measurements were carried out within the equatorial zone of each apple with a fixed distance to the fruit of $2 \mathrm{~cm}$ using the methodology proposed by ortiz et al. (2001). Three repetitions were carried out for each fruit. An extemal conditioning circuit adapts and amplifies the signal. The external circuit also filters the electrical impactor response to eliminate noise from the interesting frequency band and to prevent aliasing. An internal industry standard architecture (ISA) personal computer board connected the external system to the computer. A Windows-based software controlled the process, stored data and provided the user with an interface to manage the data and control the measurement process (Diezma-Iglesias et al, 2006). Maximum acceleration, measured in $\mathrm{m} \mathrm{s}^{-2}$ and duration of impact given in $\mathrm{ms}$ were extracted from the deceleration data registered by an accelerometer.

\subsection{Statistical analysis}

Statistica ${ }^{\text {si }}$ software was used for data analysis. The variability associated with individual measures was evaluated, but here only fruit averages were used for the analysis.

Factor analysis was carried out with 120 fruits coded as explained above. The data set included eight variables, three of which corresponded to the reference test, while the other five corresponded to non-destructive tests. The variables were referred to as listed in Table 2.

Sample values corresponded to the average of three values per fruit for each variable. As the variables were measured with different units, there were large differences between them with respect to means, variance and standard deviation. Prior to applying the factor analysis it was therefore necessary to centre and weight the data using the inverse of the standard deviation of each variable.

\section{Results}

3.1. Reference and non-destructive firmness in relation to different factors of variation

Table 3 shows the results of an ANOVA analysis of the three reference texture tests. Texture parameters were better at discriminating between fruits from different turgidity stages and storage periods than between those from different harvest dates. The puncture test was better at detecting the dehydration treatment, $F=95.37$, as compared to storage period, $F=50.86$. MT test was able to detect the effect of storage period $(F=107.17)$ better than the dehydration treatment ( $F=10.58$ and 253.33 respectively). The initial maturity stage appeared to be the least significant factor affecting variation (Table 3).

Figs. 1-3 show mean values of the three reference texture test. Fig. 1 shows mean values of maximum deformation of puncture test (MDPT) for the initial maturity stage and storage period in treated (D) (Fig. 1A) and untreated (H) (Fig. 1B) apples. This variable appeared able to differentiate between treated and untreated fruits, especially at the end of the storage, and these differences were clearer for mature fruits after 60 days of storage. These results demonstrated the capability of the puncture test to evaluate changes in turgor and hydration stage in apples, reported by García et al. (1995). This test was useful to follow changes during storage mainly for treated fruits. Using this technique, differences between mature and immature fruits can be detected for treated fruits after 60 days of storage.

Fig. 2 shows mean values of maximum force of MT (MFMT) test for initial maturity and the storage period in dehydrated (D) and hydrated $(\mathrm{H})$ apples. This test appeared capable only of following changes during storage for all fruits. Differences between maturity stages and between treated and untreated fruits couldn't be detected using this test. For treated fruit after 60 days of storage, MT test is slightly higher than for untreated fruit. The differences in firmness during storage generated by dehydration treatment can be observed using MFMT for both mature and immature fruits.

Fig. 3 shows mean values of maximum force of ball compression test (MFBCT) for initial maturity and the storage period in dehydrated (D) and hydrated $(\mathrm{H})$ fruits. This test appeared useful to follow changes during storage, especially for treated fruits. No differences between mature and immature fruits could be detected with this technique. Ball compression test was better than MT test to follow changes during storage for treated fruit (D) (Figs. 2 and 3).

According to the ANOVA shown in Table 4, the results of al] the non-destructive methodologies varied significantly during

Table 3 - F-value and p-level from ANOvA results for reference variables, studying state of maturity at harvest, storage period, and hydration state factors for Golden Smoothee apple

\begin{tabular}{|c|c|c|c|c|c|c|}
\hline \multirow[t]{3}{*}{ Texture test } & \multirow{2}{*}{\multicolumn{2}{|c|}{$\frac{\text { Puncture test }}{\text { MDPT (mm) }}$}} & \multicolumn{2}{|c|}{ Magness Taylor } & \multicolumn{2}{|c|}{ Ball compression test } \\
\hline & & & \multicolumn{2}{|c|}{ MFMT (N) } & \multicolumn{2}{|c|}{$\operatorname{MFBCT}(\mathrm{N})$} \\
\hline & $F$ & $p$ & $F$ & $p$ & $F$ & $p$ \\
\hline Maturity & 7.43 & $* *$ & 6.64 & $=$ & 0.00 & NS \\
\hline Storage period & 50.86 & "** & 107.17 & $\cdots$ & 256.77 & $\cdots$ \\
\hline Hydration & 95.37 & $\cdots$ & 10.58 & $\bullet$ & 253.33 & $\cdots$ \\
\hline Mat \Stor & 7.62 & $* * *$ & 1.99 & NS & 4.03 & $*$ \\
\hline Mat $\backslash \mathrm{Hyd}$ & 3.98 & $*$ & 1.59 & NS & 4.49 & $*$ \\
\hline Stor $\times$ Hyd & 19.03 & $\cdots$ & 9.70 & 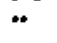 & 21.98 & $\cdots$ \\
\hline
\end{tabular}

${ }^{* *},{ }^{* *}$ and represent significant differences at the $0.001,0.01$ and 0.05 levels, respectively, and NS represents non-significant differences at $p<0.05$ 

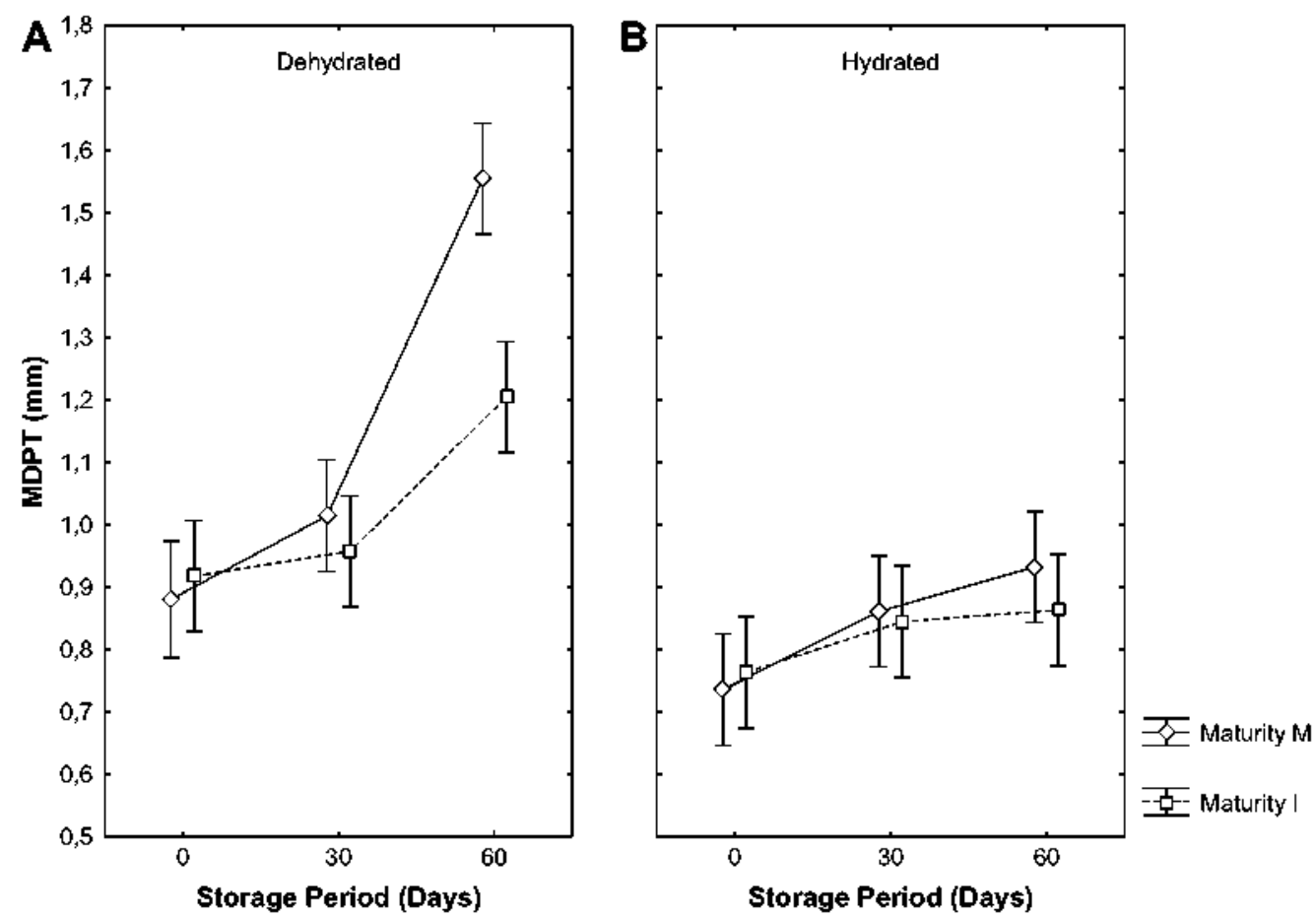

Fig. 1 - Mean values of MDPT, mm for maturity (I, immature, M, mature) and storage period $(0,3$, and 6 for 0,30 and 60 days of storage, respectively) in dehydrated (D); (A) and hydrated $(\mathrm{H})$; (B) Golden Smoothee apples. Vertical bars denote 0.95 confidence intervals. Each treatment was applied to 10 fruits sample.

storage and with the dehydration treatment, which was the most important factor (largest $F$ values). Moreover, there was a high level of agreement between dehydration as measured by deformation in the puncture test and by non-destructive contact measurements. In all cases, the correlation coefficients between non-destructive contact tests and puncture test were higher than 0.65 . For non-destructive contact tests and puncture test, $F$ values were greater for the dehydration treatment than for the storage
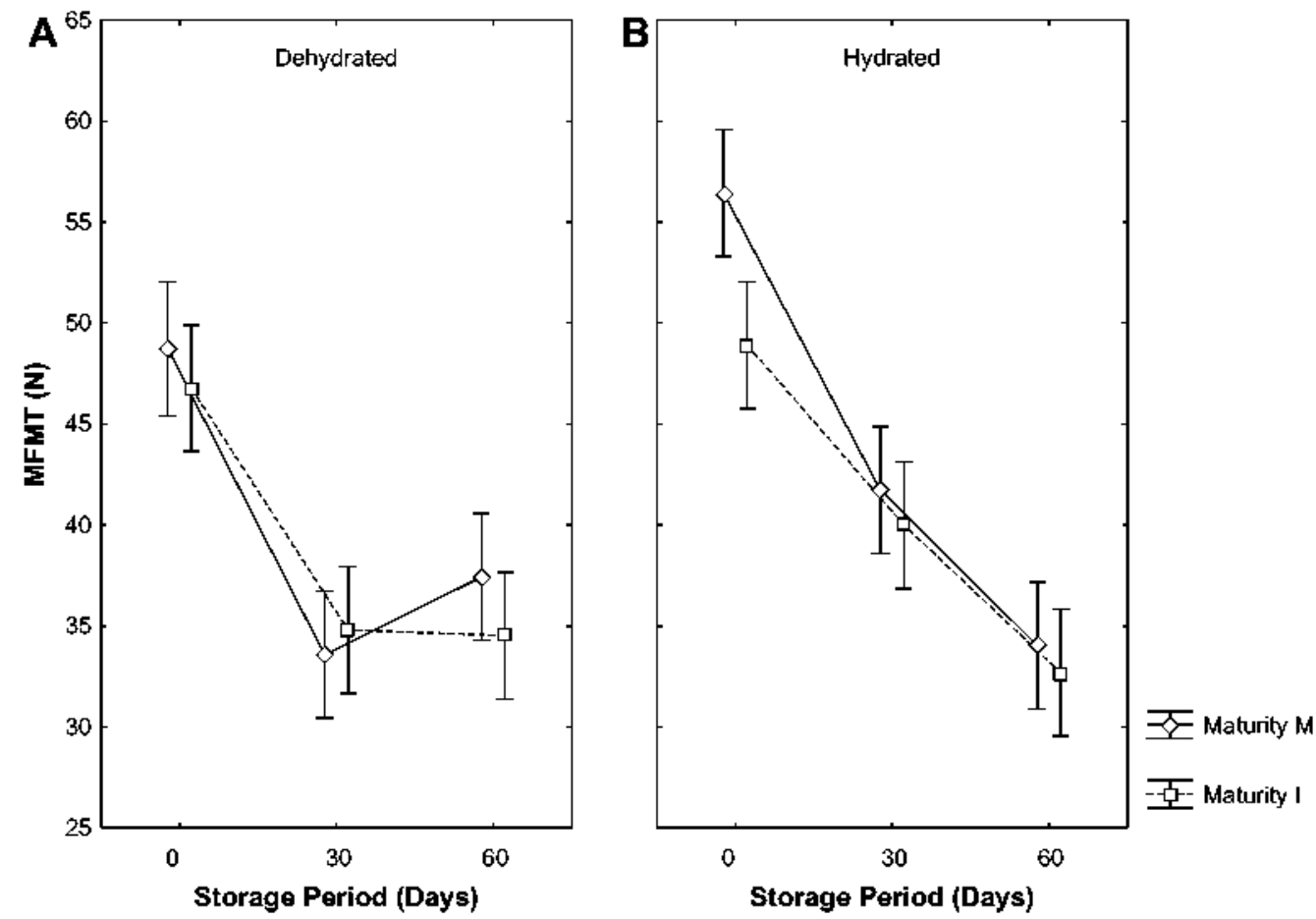

Fig. 2 - Mean values of MFMT, $N$ for maturity (I, immature, $m$, mature) and storage period $(0,3$, and 6 for 0,30 and 60 days of storage, respectively) in dehydrated (D); (A) and hydrated (H); (B) Golden Smoothee apples. Vertical bars denote 0.95 confidence intervals. 

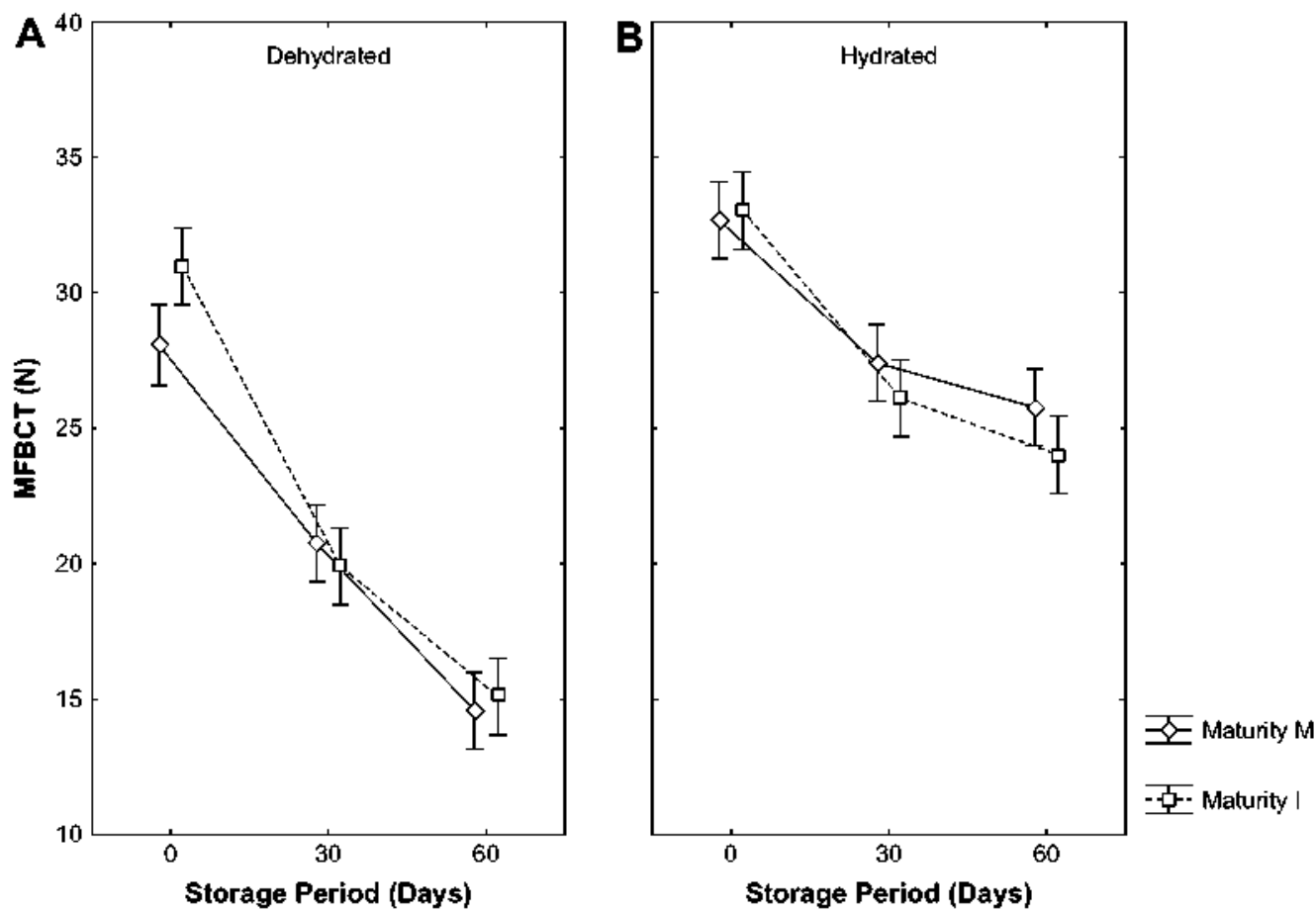

Fig. 3 - Mean values of MFBCT, $N$ for maturity (I, immature, M, mature) and storage period (0, 3, and 6 for 0,30 and 60 days of storage, respectively) in dehydrated (D); $(A)$ and hydrated $(\mathrm{H}) ;(B)$ Golden Smoothee apples. Vertical bars denote 0.95 confidence intervals.

period. There was also a significant interaction between storage and the dehydration treatment (Table 4).

The dehydration treatment had the greatest influence for the measure carried out with non-destructive impact instruments (Lateral Impact - UPM and SIQ-FT). Contact measurements were greatly affected by the dehydration treatment and less affected by storage period, although both these techniques were suitable for detecting differences between fruits with different levels of ripeness at harvest, regardless of their hydration state.

Fig. 4 shows mean values of AFIA for the initial maturity stage and storage period in treated (D) (Fig. 4A) and untreated (H) apples (Fig. 4B). Fig. 5 shows mean values of acoustic frequency (Hz) for initial maturity and storage period in treated (D) (Fig. 5A) and untreated (H) apples (Fig. 5B). According to these results, the acoustic impulse technique was not capable of detecting differences between initial maturity stages. It was only possible to detect small differences at the end of the storage period. At harvest, the dehydration treatment imposed a $10 \%$ of increase in acoustic firmness index, which was contrary to expected behaviour since dehydrated fruits are generally softer than hydrated ones. Dehydrated fruits also appeared to be harder than hydrated fruits after 60 days of storage according to acoustic measurements, but not according to the other nondestructive contact measurements. Despite these unexpected results, similar trends could be observed between MT test and acoustic firmness index for treated fruits at the end of the storage period.

Table 4 - F-value and p-level from ANOVA results for non-destructive variables, studying state of maturity at harvest, storage period, and hydration state factors for Golden Smoothee apple

\begin{tabular}{|c|c|c|c|c|c|c|c|c|c|c|}
\hline \multirow[t]{3}{*}{ Non-destructive test } & \multicolumn{4}{|c|}{ Acoustic Firmness Sensor (AFS) } & \multirow{2}{*}{\multicolumn{2}{|c|}{$\frac{\text { Impact test IQ }}{\text { IQ (IQ) }}$}} & \multicolumn{4}{|c|}{ Impact test (Lateral UPM) } \\
\hline & \multicolumn{2}{|c|}{ AFIA $\left(10^{6} \mathrm{~Hz}^{2} \mathrm{~g}^{2 / 3}\right)$} & \multicolumn{2}{|c|}{ AFRA $(\mathrm{Hz})$} & & & \multicolumn{2}{|c|}{ ACIT $\left(\mathrm{ms}^{-2}\right)$} & \multicolumn{2}{|c|}{ DUIT (ms) } \\
\hline & $\mathrm{F}$ & $p$ & $F$ & $p$ & $\mathrm{~F}$ & $p$ & $\mathrm{~F}$ & $p$ & $F$ & $p$ \\
\hline Maturity & 0.81 & NS & 1.19 & NS & 6.93 & $\approx$ & 2.04 & NS & 5.39 & $*$ \\
\hline Storage period & 37.78 & ** & 39.09 & "* & 48.17 & $\cdots$ & 14.60 & $" *$ & 69.62 & "* \\
\hline Hydration & 27.06 & $\bullet$ & 53.64 & $\cdots$ & 88.06 & $\cdots$ & 287.65 & $*$ & 186.33 & $*$ \\
\hline Mat $\times$ Stor & 1.30 & NS & 2.34 & NS & 3.05 & NS & 2.70 & NS & 0.89 & NS \\
\hline Mat $\times$ Hyd & 0.06 & NS & 0.90 & NS & 0.75 & NS & 2.96 & NS & 5.83 & $*$ \\
\hline Stor $\times$ Hyd & 21.54 & ." & 22.78 & .* & 12.86 & $\cdots$ & 17.21 & +* & 8.37 & $\cdots$ \\
\hline
\end{tabular}

"*, "* and represent significant differences at the $0.001,0.01$ and 0.05 levels, respectively, and NS represents non-significant differences at $p<0.05$. 

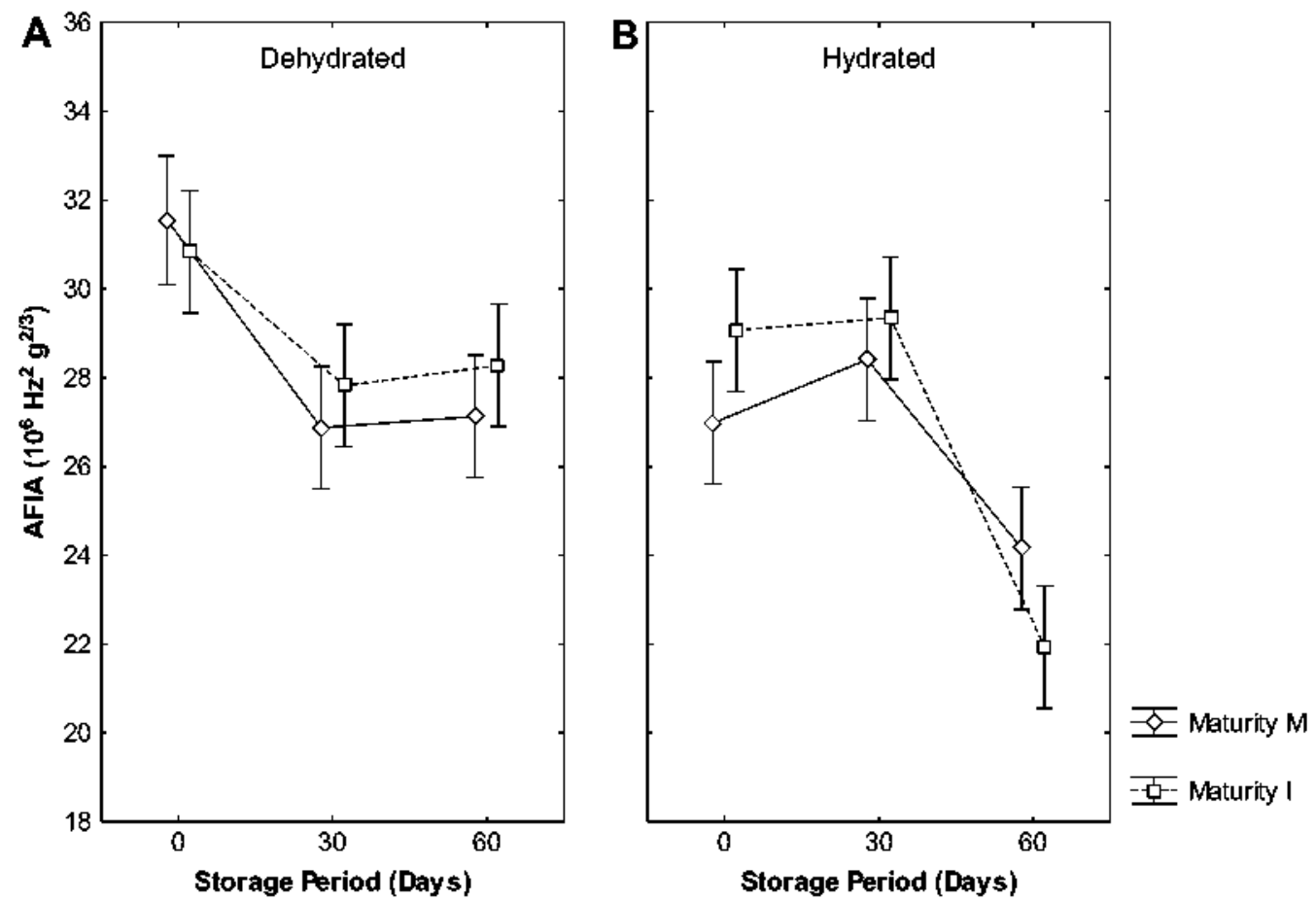

Fig. 4 - Mean values of acoustic firmness index, $10^{6} \mathrm{~Hz}^{2} \mathrm{~g}^{2 / 3}$ for maturity (I, immature, $\mathrm{M}$, mature) and storage period (0, 3, and 6 for 0,30 and 60 days of storage, respectively) in dehydrated (D); (A) and hydrated (H); (B) Golden Smoothee apples. Vertical bars denote 0.95 confidence intervals.

Fig. 6 shows mean values of IQ for initial maturity and the storage period in dehydrated (D) and hydrated (H) apples. This instrument differentiated between untreated (Fig. 6B) and treated (Fig. 6A) fruits throughout storage. Changes in treated fruits during storage were easily monitored using this instrument (Fig. 6A).

Fig. 7 shows mean values for the duration of the impact (ms) in the Lateral Impact - UPM test for initial maturity and
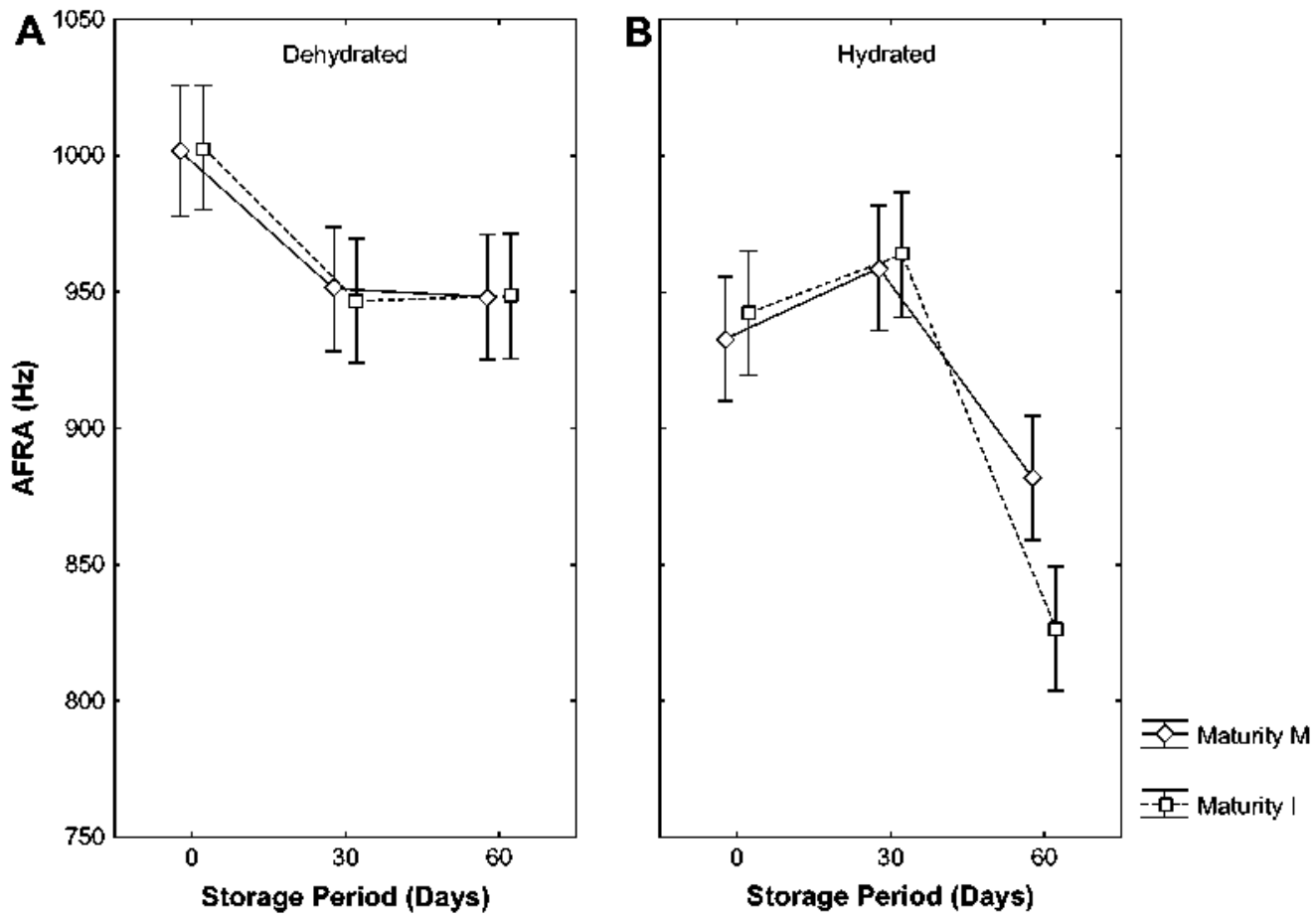

Fig. 5 - Mean values of acoustic frequency, $\mathrm{Hz}$, for maturity (I, immature, $\mathrm{M}$, mature) and storage period (0,3, and 6 for 0,30 and 60 days of storage, respectively) in dehydrated $(D)(A)$ and hydrated $(H)(B)$ Golden Smoothee apples. Vertical bars denote 0.95 confidence intervals. 

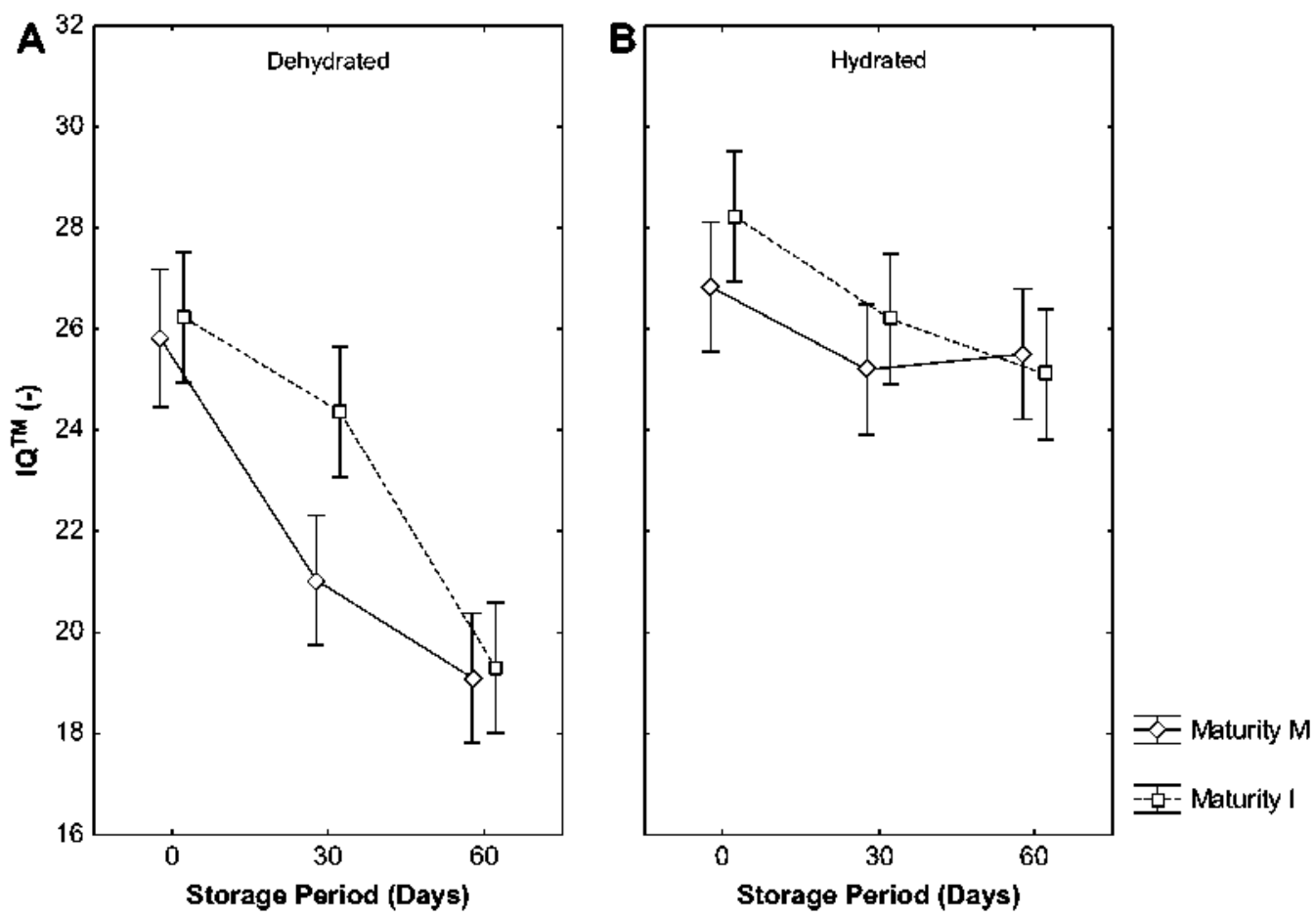

Fig. 6-Mean values of Sinclair internal quality index $\left(I Q^{\mathrm{TM}}\right)$, for maturity $(\mathrm{I}$, immature, $M$, mature) and storage period $(0,3$, and 6 for 0,30 and 60 days of storage, respectively) in dehydrated (D); (A) and hydrated (H); (B) Golden Smoothee apples. Vertical bars denote 0.95 confidence intervals.

the storage period for treated (D) and untreated $(\mathrm{H})$ apples. The duration of impact test (DUIT) was better at discriminating between untreated (Fig. 7B) and treated (Fig. 7A) fruits than between different initial maturity stages. Using this technique, it was not possible to differentiate between the injtial maturity stages of fruits at harvest. The Lateral ImpactUPM test was able to monitor fruit changes during storage (Fig. 7A and $\mathrm{B}$ ). The impact duration increased with the storage
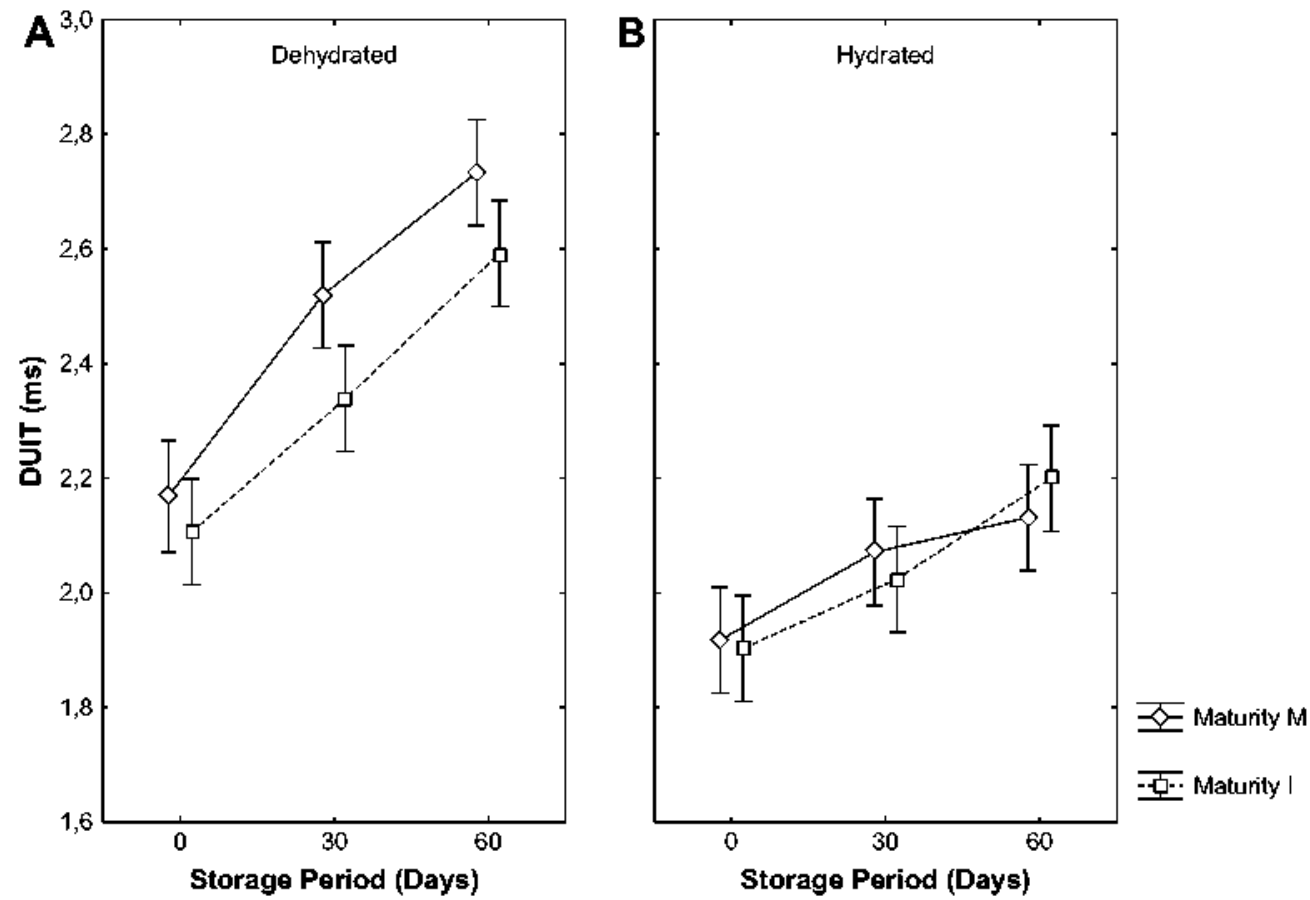

Fig. 7 - Mean values of DUIT, ms, for maturity (I, immature, M, mature) and storage period (0,3, and 6 for 0,30 and 60 days of storage, respectively) in dehydrated (D); (A) and hydrated $(\mathrm{H}) ;(\mathrm{B})$ Golden Smoothee apples. Vertical bars denote 0.95 confidence intervals. 
period: after storage, fruits had lost turgor and therefore the duration of the impact was higher.

It was possible to use the impact test to clearly distinguish between fruits that were hydrated and dehydrated. On the other hand, the Sinclair test was not only unable to recognize the hydration treatment, but was also unable to differentiate the postharvest evolution of untreated fruits. These results agree with those obtained by Jaren \& García-Pardo (2002), relating to differentiation between apples and pears through different sources of variation.

\subsection{Correlation between reference texture tests and non-destructive methodologies}

The SIQ-FT and Lateral Impact - UPM correlated well with reference texture tests, especially in the case of the ball compression ( $R=0.77$ and $R=0.87$, respectively) and puncture tests ( $R=-0.65$ and $R=0.79$, respectively) (Table 5). These relationships showed that contact measurements were highly correlated with puncture test, and were thus able to estimate changes in the hydration stage of apples that the puncture test represents (Table 5).

No correlations were found between acoustic measurements and most of the parameters from the texture test: only poor correlations between acoustic measurements and the MT test and impact test results were observed. For this cultivar, acoustic firmness index did not seem to measure the same attributes as texture and contact measurements (SIQ-FT and Lateral Impact - UPM).

\subsection{Relationships between the variables: multivariate analysis}

A factor analysis was caried out to obtain an overview of al] the samples characterized, as described in the methodology. In this analysis, $80 \%$ of total variance in the data was explained with a two-factor model. Figs. 8 and 9 show the respective loading and score plots of Factor 1 vs Factor 2 from the full data factor analysis model.

The loading plot (Fig. 8) clearly shows that the SIQ-FT test, ball compression test and skin puncture test were the most relevant tests for Factor 1, whereas acoustic variables were most relevant for Factor 2. The MT test appeared to have limited dependence of either Factor 1 or Factor 2. It was therefore only possible to establish some slight relationship between contact measurements and acoustic firmness index.
Acoustic firmness index measurements seemed to be also related to the MT test but to a lesser extent than contact measurements.

Fig. 9 presents the score plots for all fruits projected into the two factors. Most of the samples were grouped along Factor 1 and exhibited an increasing value of Factor 1 as storage period increased from 0 to 60 days. Two separate groups representing different turgidity conditions generated by the dehydration treatment and storage (MOD, IOD and M6H, I6H) can be distinguished at low and high values of Factor 2, which was mainly related to acoustic measurements (not all the data points for these treatments appear within the circles marked).

\section{Discussion}

The results showed a similar behaviour between MT firmness and acoustic firmness index at the end of the storage period for treated fruits. According to both techniques, after 30 days of storage, firmness was maintained stable or showed a slight increase. These results can be better understood by considering the effect of hot air treatment on the mechanical properties of apples. Convection drying changes the structure and composition of the material, as a result of water removal, and loss of semipermeability and destruction of the membranes. Removal of water also adds rigidity to the external layers (Lewicki \& Pawlak, 2003).

According to these results for samples corresponding to batches M0D, IOD and $\mathrm{M} 6 \mathrm{H}, \mathrm{I} 6 \mathrm{H}$, acoustic firmness index seems to offer few advantages with respect to contact measurements. As the dehydration treatment only induced a reduction in turgidity in the outermost fruit tissues, contact techniques appeared to be better able to evaluate changes generated by the dehydration treatment than acoustic techniques which obtained a global measure of the fruit. Contact techniques were also able to evaluate initial maturity at harvest.

De Ketelaere et al. (2006) noticed that with AFS there were several cases in which the repeatability error was far greater than on average: they concluded that the outliers repeatabi]ities for AFS were the result of difficulties in selecting the correct resonant frequency to use in the expression to calculate the acoustic firmness index. In our experiment, there were some batches of samples (M6H, I6H, IOD and MOD) that frequently presented abnormal trends. These points, which

Table 5 - Correlations between values of non-destructive variables and the reference texture test. Correlation coefficients (R) were calculated with $n=120$

\begin{tabular}{|c|c|c|c|c|c|c|c|}
\hline & AFRA & IQ & ACIT & DUIT & MFBCT & MFMT & MDPT \\
\hline AFlA & 0.88 & 0.08 & -0.08 & -0.11 & 0.16 & 0.31 & -0.05 \\
\hline AFRA & & -0.01 & -0.22 & 0.01 & 0.09 & 0.33 & 0.04 \\
\hline $1 Q$ & & & 0.67 & -0.78 & 0.77 & 0.47 & -0.65 \\
\hline AClT & & & & -0.87 & 0.67 & 0.17 & -0.71 \\
\hline DUIT & & & & & -0.87 & -0.46 & 0.79 \\
\hline MFBCT & & & & & & 0.68 & -0.72 \\
\hline MFMT & & & & & & & -0.29 \\
\hline MDPT & & & & & & & \\
\hline
\end{tabular}




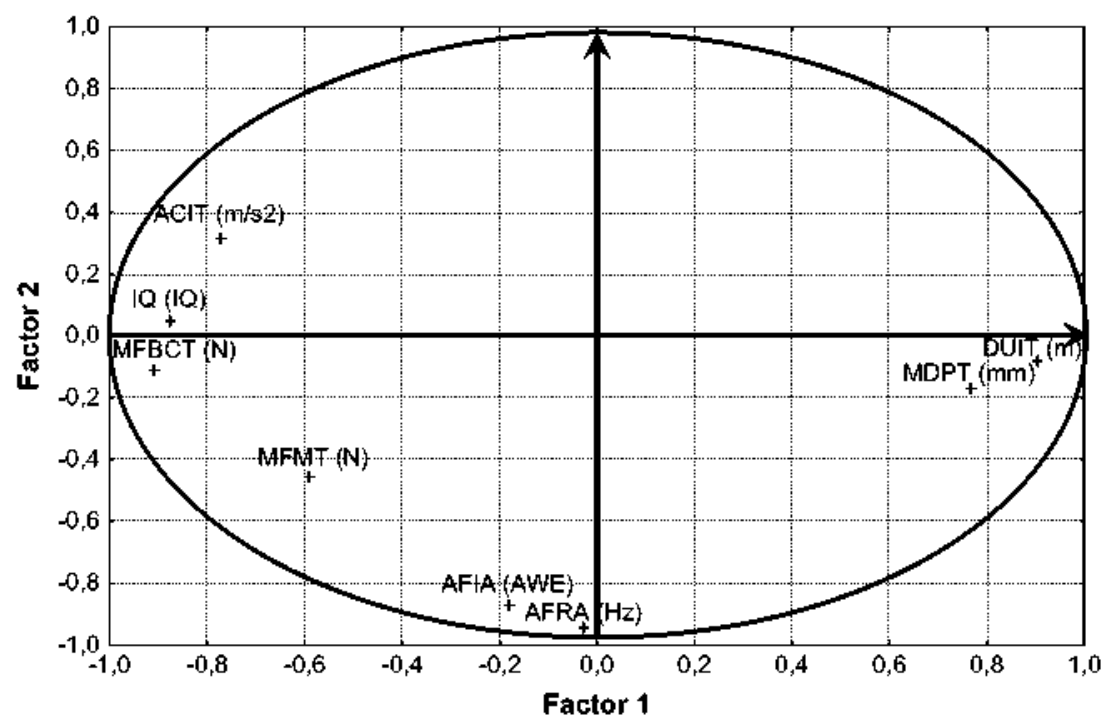

Fig. 8 - Factor analysis. Loading plots carried out using all data, $n=120$. Variables extracted from the reference texture test and non-destructive methodologies are represented in a space formed by Factor 1 and Factor 2 of the factor analysis results. Variables are labelled using codes defined in Table 2.

De Ketelaere et al. (2006) observed as outliers under our conditions, were entire batches. Measurements of AFS are therefore not accurate for extreme conditions in the north of Europe, but such extreme conditions are also frequent in many other places where fruits are picked while softer than in the north of Europe.

As users and specialists who could potentially recommend the use of this technique for measuring quality and classifying fruit, it is our responsibility to point out that in the context of different countries with different fruit production and harvesting characteristics, the use of this technique would probably be limited to certain specific conditions. However, this limitation could be overcome by adjusting the algorithm of identification of maximum frequency and thereby adapting

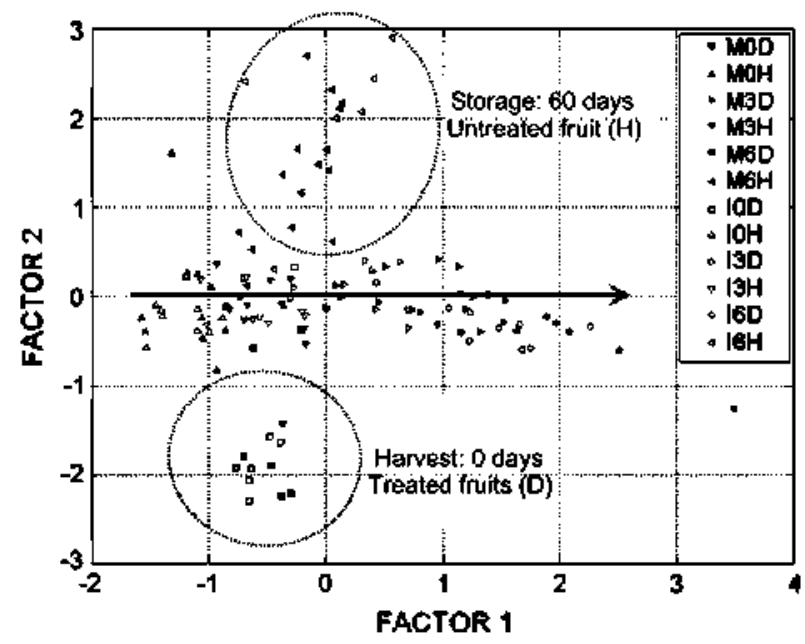

Fig. 9 - Factor analysis. Score plot of Factor 1 vs Factor 2. Samples are labelled according to the experimental design defined in Table 1. Most samples inside of the circles correspond the batches: MOD, IOD and M6H, I6H. the device to extend its potential use to a wider range of production and commercialization conditions.

Apart from under the previously identified extreme conditions, AFS does not allow users to clearly distinguish between different maturity stages, dehydration treatments or storage periods (only between treated and untreated fruits after 60 days of storage), while the SIQ-FT and Lateral Impact UPM methods do not only make it possible to observe clear differences within the same batches of fruits (data not shown), but also presented unexpected behaviour in batches with extreme conditions reported above. These findings are in line with those of Jaren and Garcia-Pardo (2002), and Shmulevich et al. (2003), who reported the ability of the contact tests to observe significant differences between batches and individual fruits.

De Ketelaere et al. (2006) reported that the AFS technique may be more sensitive for firm samples, whereas the impact technique (SIQ-FT) is more sensitive for soft specimens. This could explain the ability of the impact tests to monitor changes in apples when they have been picked softer.

Several authors have compared differences between non-destructive techniques and reported that these methodologies are sometimes reasonably well correlated with destructive measurements of firmness. Even so, it should be remembered that the two types of techniques do not measure the same fruit properties (Golding et al, 2005; Gómez et al., 2005; De Ketelaere et al., 2006; Nicolaï et al., 2006).

According to our results for apples, the dehydration process produces unexpected readings for AFS behaviour. It is in relation to hydration changes that this measure most significantly differs from the contact test. In fact, the relationship between acoustic variables and maximum deformation, as measured by the puncture test, was worse than that exhibited between contact measurements and maximum deformation due to puncture. These results could be better 
understood if combined with those of Landahl et al. (2004), who concluded that the stiffness factor of AFS is the best indicator of fruit changes during long-term storage because it is more related with changes in the cell wall structure than with changes in total turgor during harvest or short-term storage. These results of Landahl et al. (2004) are in contrast with those presented by Hertog et al. (2004), who concluded that acoustic response is largely a measure of tissue stiffness, and that tissue stiffness is based in both the cell wall mechanical strength and the tension under which the tissue is held by turgor. According to them the mechanical strength of the cell walls can be weakened by temperature sensitive enzymatic activity, whereas turgor is affected by water loss driven by water vapour pressure deficit - WVPD (which is a function of both temperature and R.H.) according to the water vapour permeance of the tissue. The contact tests appeared to be greatly affected by the dehydration treatment even when the results obtained were as expected. This is because as dehydration increases, force decreases. The differences between contact and acoustic measurements also may be related to the way they measure, as acoustic evaluates the whole fruit and is more complex while contact measurements are a local measure and present the expected trend.

In general, relationships between the non-destructive test and MT test were poor ( $\mathrm{R}$ from 0.17 to 0.47 ). This supports the observations of Nicolai et al. (2006), who stated that measures of acoustic firmness are only related to elastic properties of fruit and thus fundamentally different from those of MT firmness that measures the resistance of fruit flesh to penetration and is related to cell wall thickness and the resistance of intercellular bindings, as Landahl et al. (2003) reported. Contact measurements showed higher correlation coefficients with compression and the MT test than with acoustic measurements. These results are in line with those reported by Valero et al. (2003), and Golding et al. (2005) for peaches and are very different from those reported by Zude et al. (2006) for apples and De Belje et al. (2000) for pears.

\section{Conclusions}

According to our results, turgidity produces unexpected readings for AFS behaviour. The results obtained with this measure most differ from those obtained applying the contact test with respect to changes in hydration. In fact, the relationship between acoustic variables and deformation at maximum force as measured by the puncture test was worse than that observed between contact measurements and deformation due to puncture.

Contact measurements (Lateral Impact - UPM and SIQFT) are highly sensitive to changes in turgidity, but less able to follow changes in ripening due to storage. Both these instruments were suitable for detecting differences between fruits from different harvest dates. The Lateral Impact UPM test allowed us to identify turgid fruits better than the SIQ-FT instrument. Contact measurements showed higher correlation coefficients with reference texture tests than with acoustic measurements and were the only techniques suitable for discriminating between initial maturity stages in dehydrated fruits throughout the storage period.
Turgidity was the main source of variation for AFS, while ripening had more influence on the variation for contact measurements.

\section{Acknowledgments}

The LPF-TAG funding of this work has been covered by "Comunidad de Madrid" through TAGRALIA-CM research group and the "Universidad Politécnica de Madrid".

This work was also supported by a grant from the "Universitat de Lleida" and from INLA project RTA 02066.

\section{RE F E R E N C E S}

Bourne M C (1966). Measure of shear and compression components of puncture test. Journal of Food Science, 31, 282-291.

Chen P; Chen S; Tang S (1985). Instrument for testing the response of fruits to impact. In: Proc. ASAE Winter Meeting, Chicago, 11I, USA. August 24-27. Paper 85:3537.

Chen H; De Baerdemaeker J (1993). Effect of apple shape on acoustic measurements of firmness. Journal of Agricultural Engineering Research, 56, 253-266.

Chen P; Ruiz-Altisent M; Barreiro P (1993). Effect of impacting mass on firmness of fruits. ASAE Paper 93-6542.

Chen P; Ruiz-Altisent M (1996). A low mass impact sensor for high-speed firmness sensing of fruits. In: Paper Presented at AgEng 96 Madrid, Spain. Paper n' 96 F-003.

Chen P; Tjan Y (1998). A real-time impact sensing system for online firmness sensing of fruits. In: Proc. International Conf. Agricultural Engineering, Oslo. Paper 98F-006.

De Baerdemaeker J; Lemaitre $L$; Meire R (1982). Quality detection by frequency spectrum analysis of the fruit impact force. Transactions of the ASAE, 25(1), 175-178.

De Belie N; Schotte S; Lammertyn J; Nicolai B; De Baerdemaeker J (2000). Firmness changes of pear fruit before and after harvest with the acoustic impulse response technique. Journal Agricultural Engineering Research, 77(2), 183-191.

De Ketelaere B; Howarth M S; Crezee L; Lammertyn J; Viaene $K_{;}$ Bulens I; De Baerdemaeker J (2006). Postharvest firmness changes as measured by acoustic and low-mass impact devices: a comparison of techniques. Postharvest Biology and Technology, 41(3), 275-284.

De Smedt V; Barreiro P; Verlinden B E; Veraverbeke E A; De Baerdemaeker J; Nicolai B M (2002). A mathematical model for the development of mealiness in apples. Postharvest Biology and Technology, 25, 273-291.

Delwiche $\mathrm{M} \mathrm{J} \mathrm{(1987).} \mathrm{Theory} \mathrm{of} \mathrm{fruit} \mathrm{firmness} \mathrm{sorting} \mathrm{by} \mathrm{impact}$ forces. Transactions of the ASAE, 30, 1160-1167.

Delwiche M J; Arévalo H; Mechlschau J (1996). Second generation impact force response fruit firmmess sorter. Transactions of the ASAE, 39(3), 1025-1033.

Diezma B (2004). Propiedades acústicas aplicadas a la determinación de los parámetros de calidad intema de productos hortofrutícolas. Revista Acústica, 35, 3-4.

Diezma-Iglesias B; Ruiz-Altisent M; Barreiro P (2004). Detection of intemal quality in seedless watermelon by acoustic impulse response. Biosystems Engineering, 88(2), 221-230.

Diezma B; Valero C; Garcia-Ramos F J; Homer I; Ruiz-Altisent M; De Merlo $B ;$ Nasarre E (2005). Determination of firmness evolution of peaches during storage by combining acoustic and impact methods. Journal of Food Engineering, 77(4), 926-935. 
Diezma-Iglesias B; Valero C; García-Ramos F J; Ruiz-Altisent M (2006). Monitoring of firmness evolution of peaches during storage by combining acoustic and impact methods. Journal of Food Engineering, 77, 926-935.

García J L; Ruiz-Altisent M; Barreiro P (1995). Factors that influencing mechanical properties and bruise susceptibility of apples and pears. Journal Agricultural Engineering Research, 61, 11-18.

Golding J B; Spohr L; Newman S; Tanner D J; Orszulok E; Smale N; Graves C; McGlasson W B (2005). Non destructive assessment of peach and nectarine firmness. Acta Horticulturae, 687, 261-269.

Gómez A H; Wang J; García-Pereira A (2005). Impulse response of pear fruits and its relation to Magness Taylor during storage. Postharvest Biology and Technology, 35(2), 209-215.

Herppich W B; Herold B; Landahl S; De Baerdemaeker J (2003). Interactive effects of water status and produce texture - an evaluation of non destructive methods. Acta Horticulturae, 599, 281-288.

Hertog M; Ben-Arie R; Róth E; Nicolaii B (2004). Humidity and temperature effects on invasive and non-invasive firmness measures. Postharvest Biology and Technology, 33(1), 79-91.

Jaren C; García-Pardo E (2002). Using non-destructive impact testing for sorting fruits. Journal of Food Engineering, 53(1), 89-95.

Johnston J W; Hewett E W; Banks N H; Harker F R; Hertog M L (2001). Physical change in apple texture with fruit temperature: effects of cultivar and time in storage. Postharvest Biology and Technology, 23, 13-21.

Landahl S; Herppich W B; Herold B; Geyer M; De Baerdemaeker I (2004). A comprehensive evaluation of the interactions between produce elasticity and water status. European Journal of Horticultural Science, 69(6), 250-257.

Landahl S; Jacksók P T; De Baerdemaeker J (2003). Firmness of developing apples on the tree and shortly alter harvest measured with the acoustic impulse response. Acta Horticulturae, 600, 63-70.

Lewicki P P; Pawlak G (2003). Effect of drying on microstructure of plant tissue. Drying Technology, 21(4), 657-683.

Mohsenin N N (1970). Physical Properties of Plant and Animal Materials. Gordon and Breach Science Publishers.

Molina-Delgado D; Alegre S; Puy J; Recasens I (2009). Relationship between acoustic firmness and Magness Taylor firmness in
Royal Gala and Golden Smoothee apples. Food Science and Technology International, 15(1), 31-40.

Nicolaï B M; Beullens K; Bobelyn E; Hertog M; Vermier S; Lammertyn J (2006). Systems to characterize internal quality of fruit and vegetables. Acta Horticulturae, 712, 59-65.

Ortiz C; Barreiro P; Correa E; Riquelme F; Ruiz-Altisent M (2001) Non-destructive identification of woolly peaches using impact response and near infrared spectroscopy. Journal Agricultural Engineering Research, 78(3), 281-289.

Roth E; Kovács E; Felföldi J (2003). Investigating the firmness of stored apples by non-destructive method. Acta Horticulturae, $599,257-263$.

Shmulevich I (2003). Nondestructive texture assessment of fruits and vegetables. Acta Hoticulturae, 599, 289-296.

Shmulevich I; Galili N; Howarth M S (2003). Nondestructive dynamic testing of apples for firmness evaluation. Postharvest Biology and Technology, 29(3), 287-299.

Steinmetz V; Grochon M; Bellon V; García J L; Barreiro P; Verstreken L (1996). Sensors for fruit firmness assessment: comparison and fusion. Journal Agricultural Engineering Research, 64, 15-28.

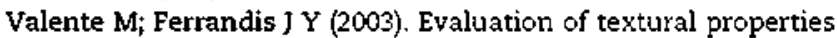
of mango tissue by a near-field acoustic method. Postharvest Biology and Technology, 29(2), 219-228.

Valero C (2001). Aplicación de la espectroscopía láser de reflactancia difusa (ERDT) a la medida de calidad interna de frutas y hortalizas. Tesis Doctoral. Escuela Técnica Superior de Ingenieros Agronomos. Universidad Poliécnica de Madrid.

Valero C; Crisosto $\mathrm{CH}$; Garner D; Bowerman E; Slaughter D (2003). Introducing nondestructive flesh color and firmness sensors to the tree fruit industry. Acta Hoticulturae, 604, 597-603.

Valero C; García-Ramos F J; De Merlo B; Ruiz-Altisent M; Howarth M S (2004). European Society of Agricultural Engineers Conference AgEng 2004, Leuven, Belgium. Comparison between Sinclair IQ firmness tester and standard destructive tests on peaches.

Zude M; Herold B; Roger J M; Bellon V; Landahl S (2006). NonDestructive test on the prediction of apple fruit flesh firmness and soluble solids content on three and in shelf life. Journal of Food Engineering, 77(2), 254-260. 